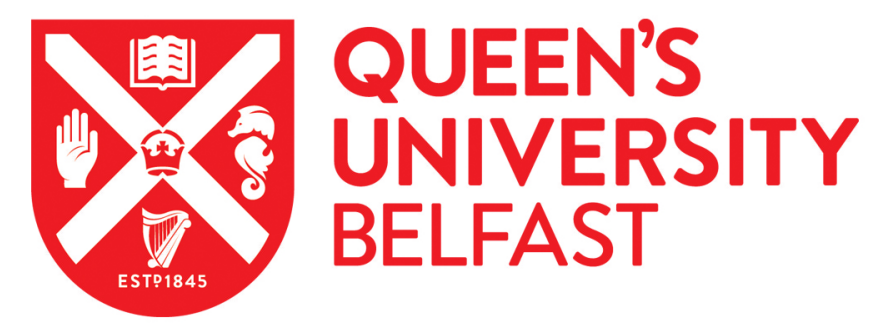

\title{
Remote consulting during and post COVID-19: An opportunity to move more?
}

Mayne, R. (2020). Remote consulting during and post COVID-19: An opportunity to move more? InnovAiT: Education and inspiration for general practice. https://doi.org/10.1177/1755738020957046

Published in:

InnovAiT: Education and inspiration for general practice

Document Version:

Peer reviewed version

Queen's University Belfast - Research Portal:

Link to publication record in Queen's University Belfast Research Portal

\section{Publisher rights}

Copyright 2020 the authors.

This manuscript is distributed under a Creative Commons Attribution-NonCommercial-NoDerivs License

(https://creativecommons.org/licenses/by-nc-nd/4.0/), which permits distribution and reproduction for non-commercial purposes, provided the author and source are cited.

\section{General rights}

Copyright for the publications made accessible via the Queen's University Belfast Research Portal is retained by the author(s) and / or other copyright owners and it is a condition of accessing these publications that users recognise and abide by the legal requirements associated with these rights.

Take down policy

The Research Portal is Queen's institutional repository that provides access to Queen's research output. Every effort has been made to ensure that content in the Research Portal does not infringe any person's rights, or applicable UK laws. If you discover content in the Research Portal that you believe breaches copyright or violates any law, please contact openaccess@qub.ac.uk. 


\title{
Remote Consulting During and Post Covid-19: An Opportunity to Move More?
}

\author{
Dr Richard Mayne
}

GP Registrar and Academic Research Trainee (ST3), Struell Surgery, Downpatrick and Queen's University Belfast

Email: rmayne02@qub.ac.uk

Twitter handle: @DrRichardMayne

The arrival of the COVID-19 pandemic caused rapid and significant changes to the traditional general practice working environment. Prior to the pandemic, the majority of patient consultations involved face-to-face interaction. In March 2020, with the rapid increase in COVID-19 cases RCGP guidance advised GPs to switch to remote consulting where possible. Remote consulting allows patient-doctor interaction to be maintained, while eliminating the risk of transmission of communicable diseases. Although remote consulting has been used more often by GPs in recent years, the unprecedented rapidity and scale of change in general practice consulting is likely to be the most significant change in the history of the profession. There are challenges and opportunities from the increase in remote consulting. The subtleties of human interaction, with all the non-verbal cues, incidental findings and extra detail provided by traditional consulting have been replaced by the dialling of phone numbers, the leaving of voicemails and the adjustment of webcams. The rich tapestry of detail from face to face consultations is unlikely to feature in general practice as it did before COVID-19.

Although many doctors and patients will miss the pre COVID-19 era, it is important to consider possible opportunities provided by the seismic shift to remote consulting. One area of interest is the effect on GP's physical activity of GPs. General Practice has long been a predominantly sedentary, desk-based occupation. Traditionally, GPs have typically sat for most of the working day during consultations, while working on the computer, making telephone calls and carrying out paperwork. An important, yet largely neglected consideration is the cost of this to our health. This is poignant given that health concerns are what we deal with throughout our working lives.

The effect of sedentary behaviour on health has been an area of research interest since the pioneering work of the epidemiologist, Jeremy Morris, in the 1940s and 1950s. Morris and colleagues demonstrated that sedentary bus drivers had higher rates of mortality from coronary heart disease than bus conductors, their more active colleagues (Morris et al., 1953a, Morris et al., 1953b). Since then, an ever-increasing weight of evidence has demonstrated the negative health effects of sedentary behaviour (Paffenbarger et al., 2001). It is now acknowledged that sedentary behaviour is associated with multiple adverse health outcomes, including mental health issues, obesity, type 2 diabetes, cardiovascular disease and dementia, as well as breast, colorectal, endometrial and ovarian cancer (Biswas et al., 2015; Hamer et al., 2009; Paffenbarger et al., 2001; Ravaglia et al., 2008; Rovio et al., 2005). As a result of these adverse health outcomes, sedentary behaviour is associated with increased all-cause mortality, even when allowing for confounding variables (Biswas et al., 2015; Chau et al., 2013; Koster et al., 2012; Katzmarzyk et al., 2009). These findings demonstrate a dose-response relationship between sedentary time and mortality (Biswas et al., 2015; Chau et al., 2013; Koster et al., 2012; Katzmarzyk et al., 2009). In light of these findings, 2019 UK physical activity guidelines state that through all stages of life, individuals should minimise their sedentary behaviour, and break up periods of 
sedentary behaviour where possible (UK Chief Medical Officers' Physical Activity Guidelines, 2019). By reducing their sedentary behaviour, and being more physically active throughout the working day, GPs could improve their health outcomes, and give a positive example to patients and colleagues. One successful example of GP involvement in the promotion of physical activity is the RCGP parkrun practice initiative that encourages practice staff and patients to engage in local parkrun events. With the relentless march of the "obesity epidemic" and associated "metabolic syndrome," is this the time for GPs to reduce their own sedentary behaviour and start moving more? This question is topical given the increased morbidity and mortality among obese individuals affected by COVID-19.

Old arguments in favour of maintaining the sedentary status quo are less relevant in light of changes to consulting in recent months. For example, there were fears that the use of standing desks by GPs could be detrimental to patient-doctor interaction, as a result of a perceived power imbalance where the doctor is looking down at the patient. However, there has long been a power imbalance in most consulting rooms, with doctors sitting in chairs superior to those of their patients. It was also argued that the introduction of intercoms or call screens to GP waiting rooms was more time-efficient and avoided "wasting" valuable time walking to call the next patient in. Instead, one patient could be replaced by another without the GP having to move an inch and allowing the time-pressed doctor a few more valuable seconds to review patient notes. With the move to more remote consulting, concerns about the use of standing desks, call screens and intercoms have now become much less relevant.

There are now many opportunities for GPs to reduce their sedentary behaviour. If remote consulting results in greater time-efficiency throughout the working day, general practice staff may have the opportunity to get out walking or running during their lunchbreaks. Telephone and video consultations can be conducted standing up, without any worry about the impact on the patient-doctor interaction. The availability of wireless headsets opens up the option of taking it a step further (pun intended) by "active consulting," where the doctor can walk around the consulting room or even use a treadmill desk while talking with patients. Other, more adventurous, novel ideas include performing lunges while waiting for the patient to answer the phone or performing a squat hold while signing a pile of scripts! For more detail, the transition from sedentary to active working has been examined in depth in the book by Katy Bowman, engagingly titled “Don't Just Sit There" (Bowman, 2016).

If we are not careful, the shift towards remote consulting could end up making GPs more sedentary than ever before. With reduced face to face consulting, opportunities to break up sedentary time with movement, such as walking to the waiting room, going on home visits, or getting out of the chair to examine patients, will be less frequent than in the pre COVID-19 era. Instead, more time will be spent talking on the phone or using computer screens, tasks most GPs typically perform sitting down.

To reduce the burden of overweight and obesity requires cultural change away from a society becoming more sedentary, towards one that is increasingly physically active. This culture change requires buy-in and engagement at all levels of society. Healthcare workers should be at the forefront, leading these changes to improve their own health and the health of patients. GPs can be key protagonists by virtue of their position in the healthcare system, where they have significant levels of patient contact and opportunities for health promotion. I would encourage everyone working in general practice to make the most of these new opportunities to move more, and lead the way to a healthier, less sedentary and more physically active society.

\section{References and further information}


Biswas A, Oh Pl, Faulkner GE, et al. (2015) Sedentary time and its association with risk for disease incidence, mortality, and hospitalization in adults: a systematic review and meta-analysis. Annals of Internal Medicine. 162(2): 123-32. DOI: 10.7326/M14-1651

Bowman, K. (2016) Don't Just Sit There: Transitioning to a Standing and Dynamic Workstation for WholeBody Health. Lotus Publishing.

Chau JY, Grunseit AC, Chey T, et al. (2013) Daily sitting time and all-cause mortality: a meta-analysis. PLoS One. 8(11): e80000. DOI: 10.1371/journal.pone.0080000

Hamer M, Stamatakis E, Steptoe A. (2009) Dose-response relationship between physical activity and mental health: the Scottish Health Survey. British Journal of Sports Medicine. 43(14): 1111-1114. DOI: 10.1136/bjsm.2008.046243

Katzmarzyk PT, Church TS, Craig CL, et al. 2009. Sitting time and mortality from all causes, cardiovascular disease, and cancer. Medicine and Science in Sports and Exercise. 41(5): 998-1005. DOI:

10.1249/MSS.0b013e3181930355

Koster A, Caserotti P, Patel KV, et al. (2012) Association of sedentary time with mortality independent of moderate to vigorous physical activity. PLoS One. 7(6): e37696. DOI: 10.1371/journal.pone.0037696

Morris JN, Heady JA, Raffle PAB, et al. (1953a) Coronary heart-disease and physical activity of work. The Lancet. 262(6795): 1053-1057. DOI: 10.1016/s0140-6736(53)90665-5

Morris JN, Heady JA, Raffle PAB, et al. (1953b) Coronary heart-disease and physical activity of work. The Lancet. 262(6796): 1111-1120. DOI: 10.1016/s0140-6736(53)91495-0

Paffenbarger RS, Jr., Blair SN, Lee IM. (2001) A history of physical activity, cardiovascular health and longevity: the scientific contributions of Jeremy N Morris, DSC, DPH, FRCP. International Journal of Epidemiology. 30(5): 1184-1192. DOI: 10.1093/ije/30.5.1184

Ravaglia G, Forti P, Lucicesare A, et al. (2008). Physical activity and dementia risk in the elderly. Findings from a prospective Italian study. Neurology. 70(19 Part 2): 1786-1794. DOI:

10.1212/01.wnl.0000296276.50595.86

Rovio S, Kåreholt I, Helkala E-L, et al. (2005). Leisure-time physical activity at midlife and the risk of dementia and Alzheimer's disease. The Lancet Neurology. 4(11): 705-711. DOI: 10.1016/S14744422(05)70198-8

UK Chief Medical Officers' Physical Activity Guidelines. 2019. Available at: https://assets.publishing.service.gov.uk/government/uploads/system/uploads/attachment data/file/83 2868/uk-chief-medical-officers-physical-activity-guidelines.pdf (accessed 10 June 2020). 